\title{
DON'T BITE OFF MORE THAN YOU CAN CHEW: PROPER TASKS FOR EXTERNAL WORK ASSIGNMENTS
}

\author{
Ricarda Bouncken, University of Bayreuth, Germany \\ Christian Lehmann, University of Bayreuth, Germany \\ Martin Ratzmann, University of Bayreuth, Germany
}

dx.doi.org/10.18374/IJBR-13-1.11

\begin{abstract}
Firms increasingly rely on external sources of labor by employing temporary workers which enhance firm capacities to adapt to changing market conditions, reduce costs, and enrich their resource bases. This study contributes to the recent research on the external workforce by examining the contribution of external workers to firms' financial and competitive performance under operational conditions. Findings base upon a survey of 235 firms in the German manufacturing industry. Results indicate that the three considered forms of external work arrangements (1) temporary work, (2) independent contracting, and (3) consulting are disparately influenced by task structure and task composition due to different qualification requirements. We show that a differentiated approach to evaluate external work arrangements is necessary and advantageous to increase firm performance and competitiveness.
\end{abstract}

Keywords: External Work Arrangements, Temporary Work, Independent Contracting, Consulting, Task Structure 